ARTIG0

Recebido em: 21/02/2017

Aceito em: 02/08/2017

\title{
A biblioteca móvel e o hábito da leitura: estudo de caso do BiblioSESC em Bairros de Salvador
}

The mobile library and the reading habits: a case study of BiblioSESC in Salvador's neighborhood

\author{
Ingrid Paixão de JESUS (ingridpaixao191@gmail.com)* \\ Raquel do Rosário SANTOS (quelrosario@gmail.com)** \\ Ana Claudia Medeiros de SOUSA (ana.violista@gmail.com)** \\ * Graduado em Biblioteconomia e Documentação - UFBA. \\ ** Professora do Instituto de Ciência da Informação - UFBA.
}

\section{Resumo}

Trata-se de um estudo descritivo, cujo objetivo foi analisar se e como ocorre o incentivo ao hábito da leitura por meio das atividades do BiblioSESC. Para tanto, foi adotada a técnica de aplicação de questionário junto aos usuários, para fins de análise sobre o incentivo ao hábito de leitura em três Bairros de Salvador, os quais foram contemplados com a programação da Biblioteca Móvel do SESC em 2016. Assim, observou-se que a referida Biblioteca Móvel tem incentivado o hábito da leitura. Quanto aos leitores, estes passaram a ser protagonistas sociais, auxiliando na aproximação de outros sujeitos com a leitura.

Palavras-chave: Leitura. BiblioSESC. Hábito de leitura. Biblioteca Móvel.

\begin{abstract}
This is a descriptive study, whose objective was to analyze if and how the incentive to the habit of reading occurs through the activities of BiblioSESC. Therefore, the questionnaire application technique was adopted with the users, for the purpose of analysis on the incentive to the habit of reading in three neighborhoods of Salvador, which were contemplate with the programming of the mobile library of SESC in 2016. Thus, one observed the referred Mobile Library has encouraged the habit of reading. As for the readers, these became social protagonists, helping in the approach of others subjects with the reading.
\end{abstract}

Keywords: Reading. BiblioSESC. Reading habits. Mobile Library.

v. 22 , n. 50,2017 p. 102-113

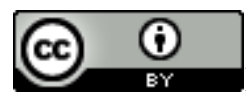

sta obra está licenciada sob uma Licença Creative Commons 


\section{INTRODUÇÃO}

Pensar na biblioteca como um dispositivo informacional e cultural foi o principal motivador que justificou a escolha temática desta pesquisa, pois, a biblioteca exerce grande influência no desenvolvimento dos sujeitos, especialmente quando os auxilia em sua formação enquanto leitores autônomos e protagonistas sociais.

Refletindo sobre a importância que têm as bibliotecas, chama atenção a atuação do Serviço Social do Comércio (Sesc) na área. A Instituição possui a maior rede privada de bibliotecas do país. Apenas na Bahia a Rede Sesc de Bibliotecas conta mais de nove bibliotecas fixas em plena atividade, um posto de leitura e o serviço da Biblioteca Móvel, denominado BiblioSESC, a qual possui serviços gratuitos, que não abrangem apenas os comerciários e seus dependentes, mas também a toda comunidade do Bairro onde a Biblioteca Móvel realiza a ação durante a semana, ou seja, semanalmente a Biblioteca Móvel se desloca para Bairros diferentes e a comunidade destes passa a ter acesso ao projeto e suas atividades, tais como consulta local e empréstimo domiciliar. O BiblioSESC tem como principal objetivo a formação de público leitor e para isso amplia as condições de acesso ao livro e à leitura encurtando distâncias, "andando" de bairro em bairro.

Neste contexto, por entender a relevância das atividades desenvolvidas pelo BiblioSESC, especialmente aquelas relacionadas à leitura, justificou-se a realização deste artigo que teve a seguinte questão norteadora: se e como ocorre o incentivo ao hábito da leitura por meio das atuações desenvolvidas pelo BiblioSESC.

Os resultados deste artigo apontaram que a Biblioteca Móvel do Sesc fomenta a leitura e auxilia os usuários a se desenvolverem como leitores. Nesse sentido, o BiblioSESC diminui a distância entre o leitor e o livro, permitindo o incentivo à leitura e cultivando o hábito de ler entre pessoas que já exercem essa prática.

\section{ESPAÇO DA BIBLIOTECA E SUA RELAÇÃO COM O HÁBITO DA LEITURA}

Para os sujeitos, a leitura é uma das maiores aptidões a ser desenvolvida, isso porque, também é por meio desta prática que se adquire e desenvolve o conhecimento. Desde o momento em que nascemos começamos a perceber nossa necessidade de experimentar, comunicar e expressar. Nesse sentido, a leitura se divide e se diferencia em duas vertentes: a leitura do mundo e a leitura da palavra. Segundo Freire (2011, p. 9), "[...] a leitura do mundo precede a leitura da palavra, daí que a posterior leitura desta não possa prescindir da continuidade da leitura daquele." Não significa que são ou estão divididas, ou que não se relacionam. Ao contrário! A leitura do mundo e a leitura da palavra estão a todo o momento se completando, embora a leitura do mundo anteceda a leitura da palavra.

Um leitor proficiente é aquele capaz de realizar uma relação constante entre a leitura de um texto com seu conhecimento e suas experiências anteriores e, a partir dessas ações, interferir em sua realidade, seja por meio de novos registros da fala, ou mesmo de suas atividades. Para Martins (1986) a leitura não se restringe aos signos, mas abrange a compreensão da realidade e das interpretações do que acontece ao nosso redor, pois tudo o que é percebido (apresentado objetivamente) influencia nas nossas reações (respostas subjetivas) e esta condição estimulada definirá os textos escritos. Assim, é relevante que os sujeitos não apenas decodifiquem os signos, mas que compreendam, interpretem, relacionem a palavra escrita com a sua realidade, sendo possível modificar sua visão do mundo e interferir nele.

A discussão sobre o gosto e hábito da leitura tem sido frequente no meio dos educadores e estudiosos. No entanto, pouco se tem realizado quanto à formação de cidadãos quanto ao gosto de ler. Sobre isto, Bortolin (2007, p. 1) diz que: 
Os familiares deveriam ser os primeiros mediadores de leitura, pois são os primeiros elos da criança com o mundo. Entretanto, os pais e demais membros da família, em geral não têm a dimensão da influência que podem exercer sobre as crianças, no sentido de motivá-las à leitura [...]

A partir da reflexão apresentada por Bortolin (2007) pode-se afirmar que é na família que os sujeitos poderiam despertar o primeiro interesse pela leitura. Entretanto, algumas barreiras podem ser impostas a uma parcela da sociedade menos favorecida economicamente, àquela parcela que não possui condições financeiras; lhe faltam incentivos e acesso à dispositivos culturais e/ou que ainda que possua esses recursos não tem o hábito de ler. Nesse meio familiar, que apresenta tais características, torna-se mais difícil o hábito da leitura iniciar ainda na infância. Nesse contexto, os dispositivos culturais e informacionais, tais como a escola e a biblioteca, podem favorecer o acesso à informação, e mais que o acesso aos livros e itens informacionais, caberá a esses dispositivos a promoção de ações que favoreça as condições propícias para o desenvolvimento do hábito de ler. Como afirmam Silva e Bortolin (2006, p. 17) "[...] cabe aos mediadores de leitura, entre eles, familiares, professores e bibliotecários, provocar na mais tenra idade o 'paladar', ou seja, o gosto pela leitura." Dessa maneira, cabem a estes atores desenvolverem ações de mediação da leitura, como contação de histórias, entre outras práticas que potencializem o compartilhamento de vivências e experiências, entre outras ações que possibilitem a leitura da palavra e de mundo.

Nessa perspectiva, vale destacar a diferença entre o gosto e o hábito da leitura. Embora sejam relacionados e se complementem, existe uma diferença prática, pois existem sujeitos que gostam de ler, contudo, não mantém esse hábito entre suas atividades cotidianas. Isso, muitas vezes, se deve ao fato de muitos leitores se depararem com circunstâncias como falta de tempo para ler, ausência de técnica de leitura, ou pouca qualidade dos conteúdos que têm acesso. Villardi (1999, p. 94) afirma que:

O importante é não obrigar ninguém a nada, mas atrair, mostrar como tudo aquilo que se está fazendo ali é bom e divertido, até que se crie uma intimidade, uma autonomia capaz de gerar uma demanda espontânea pela leitura, que se consolidará nas atividades livres.

Nesta conjuntura, é importante compreender que cada leitor possui necessidades diferentes, ou seja, entende-se que o sujeito dentro de suas particularidades, traz consigo suas características identitárias que correspondem a sua estrutura social. Portanto, os mediadores da informação devem considerar o perfil e as demandas dos usuários, ação que remete a Ranganathan (2009) quando afirma que os livros são para o leitor; e cada leitor, o seu livro.

Por meio da leitura o sujeito amplia suas perspectivas, compreensão e entendimento. Por isso, é imprescindível a realização de atividades que possam desenvolver o gosto e o hábito de ler. Dessa maneira, atividades que despertem o gosto e o prazer pela leitura devem ser entendidas e desenvolvidas com responsabilidade social de modo a contemplar toda sociedade. Assim, a biblioteca apresenta-se como um ambiente que pode potencializar o desenvolvimento do gosto e hábito da leitura, como também contribuir para a realização da mesma já que seu ambiente físico é propício para essa prática.

A biblioteca sofreu intensas transformações ao longo do tempo, mas continuou mantendo perceptível sua influência na vida e no desenvolvimento dos leitores, especialmente por sua contribuição para o acesso e construção do conhecimento. Para alcançar o objetivo de favorecer o acesso, o uso e a apropriação 
da informação, a biblioteca deve-se comportar de acordo com a indicação realizada por Santos (2012), quando afirma que este ambiente deve considerar as diversas formas de compartilhamento de informações e atuar de maneira proativa, desenvolvendo estratégias para que os usuários em potencial se tornem reais, de modo que na interação com outros sujeitos possam disseminar uma consciência sobre o papel relevante da biblioteca, além de ampliar a quantidade de usuários ativos e participantes em seu ambiente. Dessa maneira, pode-se atribuir à biblioteca a função de potencializadora na formação de leitores, por apresentar não apenas informações de interesse que motivam a leitura, mas o ambiente propício para o encontro, desenvolvimento e produção do conhecimento individual e coletivo.

Segundo Bortolin (2010, p. 115), “[...] o bibliotecário não pode se esquivar de atividades direcionadas ao auxílio à leitura, visto que o ato de ler precede o ato de se informar, descobrir e investigar." Portanto, a tarefa de mediar leitura é tão fundamental quanto potencializar o acesso aos documentos (impressos e eletrônicos). Assim, é relevante que por meio da contribuição do mediador no processo de aprendizagem das mais diversas formas de leitura, como também em suas práticas, o leitor possa atingir um nível maior de complexidade no processo de ler e produzir sentidos.

As bibliotecas podem se apresentar como importantes aliadas, não apenas por favorecerem a leitura da palavra, através do acesso ao acervo, como também, por realizar a aproximação entre os sujeitos, potencializando a troca de conhecimento, a comunicação e interação entre eles, a "leitura de mundo". Assim, a biblioteca caracteriza-se como um ambiente mediador e dialógico, conforme afirma Gomes (2014, p. 6, grifo do autor),

Toda experiência humana é dependente das práticas de comunicação, como também da transmissão cultural, que constituem o locus da mediação, envolvendo um processo de compartilhamentos objetivo e intersubjetivo por meio dos quais os sujeitos envolvidos nesse compartilhamento sempre geram significações. Por esta razão a ação mediadora é compreendida como uma ação essencialmente pautada na dialogia.

Como dispositivo importante na realização da prática da leitura, destacam-se as bibliotecas que, em suas várias tipologias, auxiliam aos leitores na busca, acesso e apropriação da informação. Entre os tipos de bibliotecas podem ser citadas: a biblioteca Escolar; biblioteca Pública; biblioteca Especializada; biblioteca Nacional, biblioteca Universitária, biblioteca Comunitária que pode ser na modalidade de biblioteca Móvel. Dessa maneira, as bibliotecas podem proporcionar o enriquecimento cultural, social e cognitivo, seja a um público específico ou a qualquer sujeito social, que ao frequentarem este ambiente, poderão ter acesso aos recursos informacionais favorecendo o desenvolvimento de competências e atitudes, entre elas de leitura, que auxiliam seu desenvolvimento na sociedade da informação.

Entre as modalidades de bibliotecas, a biblioteca móvel possui um diferencial, ao levar os materiais informacionais até o leitor e assim contribuir para a disseminação e circulação do conhecimento. Como o próprio nome transmite a ideia, o sentido da biblioteca móvel não é permanecer por um longo período em um local, mas auxiliar, por meio de suas atuações, os sujeitos em suas necessidades informacionais momentâneas e a perceberem a necessidade de construírem a sua própria biblioteca comunitária, ou da consciência de que eles precisam ter acesso à informação para modificar a realidade.

Dessa maneira, as bibliotecas móveis, que são veículos adaptados para a acomodação dos livros, vão onde não se espera que a sociedade a procure, encurtando a distância entre o livro e o leitor. Esses veículos são adaptados para 
organizar e disponibilizar os materiais informacionais e assim se aproximam com facilidade da comunidade, resultando em uma relação de interatividade com os moradores e possibilitando a realização de atividades dinâmicas, que visam contribuir com a leitura.

\section{METODOLOGIA}

Para compreender se e como ocorre o incentivo ao hábito da leitura por meio das atividades desenvolvidas pelo BiblioSESC foram traçados objetivos tais como: analisar o perfil social e cultural dos usuários do BiblioSESC, relacionando com a possível formação dos mesmos enquanto leitores; identificar se os usuários do BiblioSESC utilizam as atividades informacionais para o desenvolvimento da leitura; identificar as necessidades e motivações para a realização da leitura dos usuários do BiblioSESC; e investigar as contribuições desta biblioteca móvel para a formação do leitor.

O BiblioSESC foi definido como ambiente de investigação por ter sido possível apreender a relevância da sua atuação, bem como os esforços para alcançar objetivos direcionados a auxiliar a formação do leitor e seu desenvolvimento enquanto sujeito social. Contudo, pela extensão das atividades e público atendido, pois esta biblioteca móvel realiza visitas semanais em cada um dos dez bairros pertencentes a cidade de Salvador, na Bahia, que são selecionados anualmente, a pesquisa delimitou-se aos residentes nos Bairros de Paripe, Mussurunga e Nordeste de Amaralina. A seleção destes Bairros se justifica por serem eles os que possuem o maior número de empréstimos realizados no BiblioSESC. Assim, o primeiro critério foi por intencionalidade, selecionando bairros com o maior número de empréstimos.

É importante destacar que também foi desenvolvido um segundo critério de seleção da amostra, por acessibilidade, sendo os usuários que estiveram presentes no BiblioSESC no período da coleta dos dados.

Quanto ao procedimento de coleta de dados, vale destacar que a pesquisa foi realizada entre o período de agosto e setembro de 2016, durante a realização das atividades do BiblioSESC nos Bairros, das $9 \mathrm{~h} 30 \mathrm{~min}$ às $12 \mathrm{~h}$ e das $13 \mathrm{~h}$ às $15 \mathrm{~h} 30 \mathrm{~min}$. Para atingir os objetivos propostos pela pesquisa, foi utilizado como instrumento de coleta de dados o questionário, contendo 27 perguntas, sendo estas abertas e fechadas, podendo os usuários indicarem mais de uma alternativa.

Dessa maneira, foi aplicado o questionário junto aos usuários da Biblioteca Móvel do Sesc, residentes nos Bairros Paripe, Mussurunga e Nordeste de Amaralina, na cidade de Salvador, tendo o retorno de 40 leitores, participantes desta pesquisa, com faixa etária acima de 14 anos. A aplicação do questionário ocorreu no momento em que o usuário chegou ao espaço da Biblioteca Móvel, após a explicação do objetivo da pesquisa e apresentação do questionário.

$\mathrm{Na}$ etapa relativa a análise dos dados coletados, o tratamento das informações obtidas por meio da aplicação dos questionários, além da abordagem qualitativa, também foi adotada a abordagem quantitativa, que foram apresentados em forma de gráficos.

\section{APRESENTAÇÃO E DISCUSSÃO DOS RESULTADOS}

Ao tratar sobre o hábito da leitura, buscou-se, inicialmente, caracterizar a amostra (40 leitores) quanto ao perfil social dos usuários do BiblioSESC, relacionando com a possível formação deles enquanto leitores, desses 40 participantes da pesquisa: 27 estão cursando o nível médio; 6 cursam o nível fundamental; 4 possuem nível superior completo; 3 têm o ensino superior incompleto. Percebe-se que a maior parte dos usuários cursa o nível médio. Evidencia-se assim, a diversidade de usuários. Dessa maneira, o BiblioSESC deve 
estar preparada para atender esses usuários, tanto em relação aos tipos de itens informacionais, quanto na realização de suas atividades. Assim, é relevante que o BiblioSESC constantemente identifique a característica dos sujeitos que fazem uso de seus produtos e serviços, de modo a melhor suprir suas expectativas e necessidades informacionais.

Para responder ao objetivo referente às preferências de leitura, os usuários poderiam optar por mais de uma alternativa, contudo: 30 respondentes não especificaram os assuntos que os motivam a realizar a leitura. Por outro lado: 19 indicaram que leem por distração; 7 leem por motivos religiosos; 4 para obter atualização profissionais.

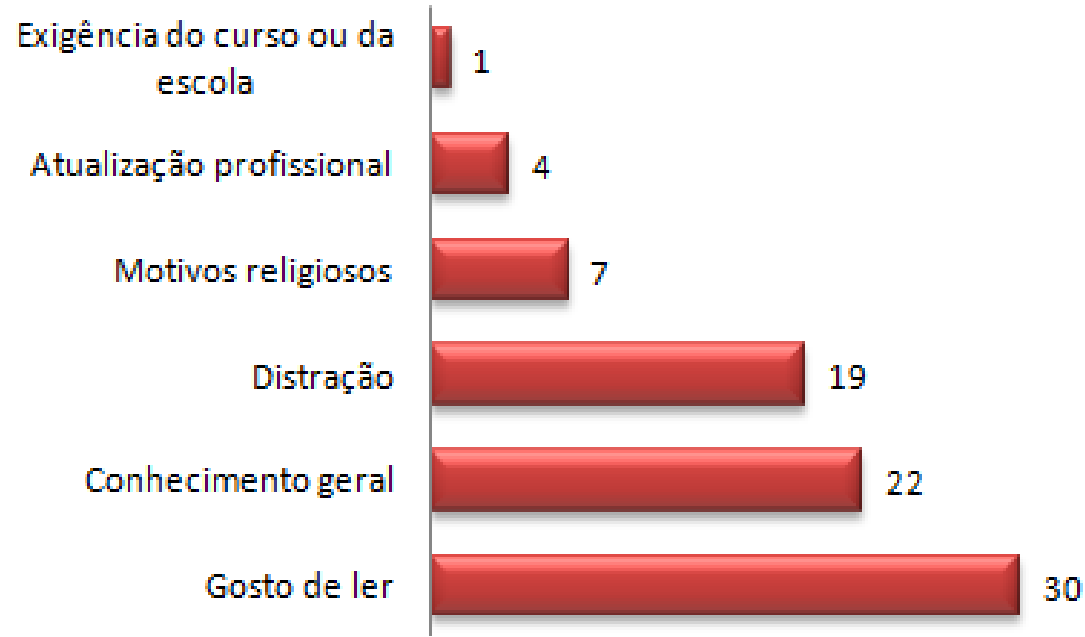

Gráfico 1: Principal motivação pela leitura.

Fonte: Dados da pesquisa.

Ainda, ao observar o Gráfico 1, constata-se que 22 usuários leem em busca de conhecimento geral, esse dado se aproxima da indicação realizada pelos 19 respondentes, que justificaram a distração como motivo para ler e que, portanto, são desprendidos de uma obrigação que poderiam condicioná-los à leitura. Assim, esse resultado pode expressar que parte significativa dos respondentes gostam de ler sem necessariamente especificar um motivo para isso, ou seja, leem por prazer.

Outro objetivo que a pesquisa investigou foi se as atividades do BiblioSESC favorecem a leitura, sendo possível identificar que dos 40 participantes da pesquisa, parte significativa, 30 deles, consideram ótima a qualidade dos serviços oferecidos pelo BiblioSESC. Além desses, outros 8 usuários classificam como bons os serviços desenvolvidos por essa Biblioteca. Vale registrar que, durante a coleta de dados, uma leitora comentou sobre a excelente recepção e comunicação que há entre os funcionários e os usuários. Assim, observa-se que as atividades desenvolvidas pelo BiblioSESC vêm atingindo positivamente as expectativas e avaliação dos usuários.

A partir desse resultado, pode-se afirmar que o BiblioSESC tem cumprido um dos seus principais objetivos, que é a satisfação dos usuários. Ao atuar dessa maneira, essa Biblioteca cumpre o papel destacado por Gomes (2014), de ambiente mediador da informação, mediando polos (instâncias sociais, sujeitos sociais e dispositivos culturais), e que, por meio dessa ação, todos os sujeitos envolvidos podem ter a oportunidade de encontrar novas possibilidades e potencialidades.

Entretanto, vale citar, que 2 usuários ainda indicaram que os serviços precisam melhorar. Duas considerações podem ser realizadas: a primeira quanto à necessidade do BiblioSESC avaliar seus serviços e buscar melhoria contínua para atender seus usuários; outra, referente à ampliação do olhar crítico do usuário, à ampliação de suas necessidades e buscas, gerando novas demandas. Tanto a 
primeira consideração quanto a segunda demandam uma postura proativa por parte da Biblioteca.

Para auxiliar os usuários a ampliarem ou desenvolverem seu gosto pela leitura, a Biblioteca precisa disponibilizar e motivar o uso dos materiais informacionais. Contudo, prioritariamente, é preciso atrair esses usuários para o ambiente da Biblioteca.

0 questionário buscou levantar também, quanto à frequência de visita à biblioteca. Assim, 29 usuários realizam a visita ao BiblioSESC semanalmente. Esse resultado demonstra uma assiduidade à Biblioteca móvel, revelando um interesse constante do leitor. Apenas 9 pessoas responderam que frequentam mensalmente e 2 usuários visitam a cada dois meses. Assim, parte significativa frequenta semanalmente o BiblioSESC, ou seja, sempre que essa Biblioteca está presente em seu Bairro.

O BiblioSESC tem atraído os usuários para seu ambiente, conforme o resultado apresentado, mas precisa estreitar os laços com aqueles que só utilizam seu ambiente, produtos e serviços com maior intervalo de tempo. Ao adotar essa postura, de tentar atrair os usuários para seu ambiente, a Biblioteca demonstra que entende que a principal razão de existir é o usuário, e é para ele que a Biblioteca desenvolve todas as suas ações e atividades.

Tais resultados possuem relação com os dados que descrevem a frequência de uso dos produtos e serviços ofertados pelo BiblioSESC. Desse modo, evidenciouse que 25 usuários utilizam o serviço de empréstimo semanalmente. Pode-se inferir que, ao visitar a Biblioteca, os usuários pegam materiais informacionais. Assim, os usuários não apenas visitam o ambiente da Biblioteca, mas utilizam os serviços e produtos ofertados pela mesma.

Por meio desse resultado, é evidenciado que 95\% dos usuários participantes da pesquisa adquirem livros por empréstimo. No caso do BiblioSESC, o leitor permanece com o livro no período de sete dias, ou seja, até a próxima visita naquele bairro, podendo renovar o empréstimo, se houver necessidade.

Também foi investigado o motivo que impulsionou os usuários a utilizarem os serviços do BiblioSESC. A partir da observação do Gráfico 2, percebe-se que os usuários poderiam escolher mais de uma alternativa, no entanto, mesmo após tantos anos de existência, a Biblioteca continua despertando a curiosidade de seus usuários e foi esse o maior motivo que levou parte significativa dos sujeitos a procurarem o BiblioSESC (22 leitores), em seguida, outra justificativa, também bastante indicada, refere-se à necessidade de leitura (20 usuários).

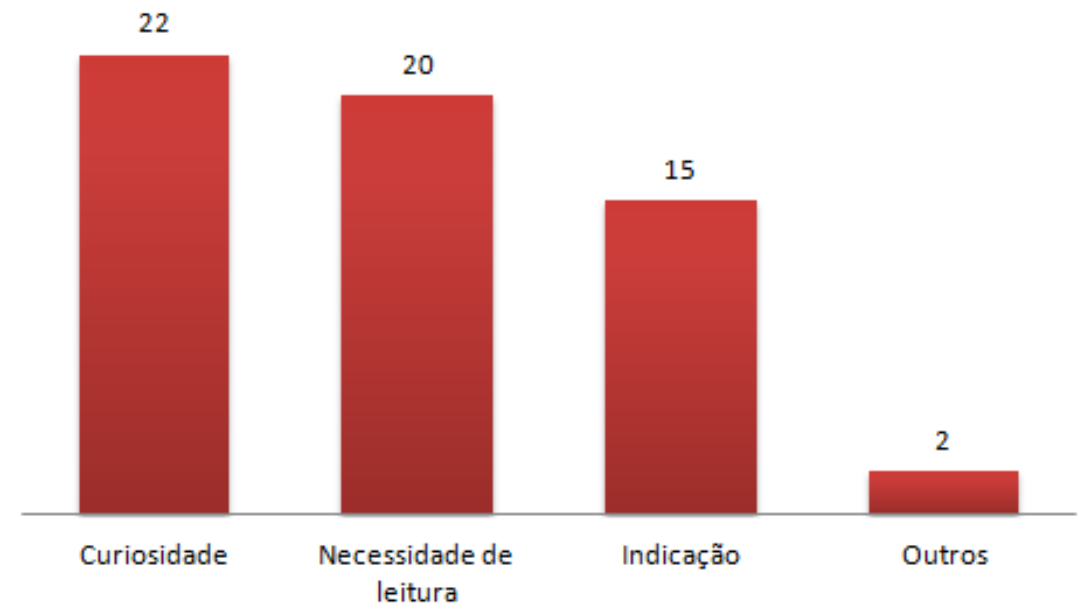

Gráfico 2: Motivos dos usuários utilizarem os serviços e produtos do BiblioSESC. Fonte: Dados da pesquisa. 
Quando os 22 usuários indicaram a justificativa "curiosidade", eles estavam mencionando também que foram ao BiblioSESC sem interferência ou indicação de outros sujeitos ou instituições. Esse resultado soma-se aos outros 20 usuários, que, em parte, podem ser os mesmos que foram ao BiblioSESC por uma necessidade informacional. Dessa maneira, cabe à Biblioteca divulgar para os usuários potenciais seus serviços e produtos, e tornar visível para eles sua missão e objetivos, como podem contribuir para o crescimento deles. A Biblioteca não pode ficar passiva, esperando que os usuários venham até ela, é preciso que ela torne-se atrativa aos usuários. Essa afirmação se aproxima dos princípios apresentados por Ranganathan (2009) quando diz que os livros são para o leitor; e cada leitor, o seu livro; isso significa essencialmente a necessidade de realizar a divulgação da Biblioteca, pois é centrado nessa ação, que a Biblioteca vai atrair os usuários e identificar os leitores potenciais, com suas necessidades e desejos informacionais.

Durante a pesquisa, foi identificada a necessidade de investigar se o BiblioSESC realiza o estímulo à leitura, praticando atividades que aproximam os seus usuários da prática de ler, respondendo, portanto, a indagação referente a participação dos usuários nas atividades realizadas pela Biblioteca Móvel. Nessa conjuntura, dos 40 participantes, 38 afirmam sobre a interferência da Biblioteca quanto ao incentivo à leitura. Enquanto, apenas 2 respondentes informaram que não houve o incentivo a ler por meio do trabalho do BiblioSESC. Estes alegam que trouxeram esse incentivo antes mesmo de conhecerem a Biblioteca Móvel, a contribuição foi apenas no sentido de manter esse hábito. Esse resultado confirma o papel mediador realizado por esse ambiente, pois, além disso, interfere positivamente na realização e ampliação da prática da leitura. Ao comportar-se assim, o BiblioSESC confirma o que Bortolin e Almeida Júnior (2007) enfatizam, quanto à necessidade de levar a leitura a diferentes espaços, fazendo com que a biblioteca cumpra uma de suas principais funções, incentivar a leitura, abrindo espaços para que todos os indivíduos (nas diversas faixas etárias) sintam-se "desejosos" de ler sempre.

O questionário buscou ainda identificar ações que melhoraram a partir da frequência dos usuários ao BiblioSESC, os dados evidenciam melhoria na desenvoltura dos usuários. Uma vez que, 16 usuários indicaram mudanças positivas na realização de debate sobre assuntos de interesse, após frequentarem 0 BiblioSESC. Pode-se inferir que, não somente a leitura enriqueceu seus conhecimentos, mas o ambiente da Biblioteca Móvel proporcionou que isso fosse possível, especialmente, por reunir e motivar os sujeitos no que tange ao compartilhamento de seus conhecimentos e experiências, prática sinalizada por Santos (2012).

Constatou-se ainda, que 11 usuários afirmaram que passaram a escrever melhor depois que começaram a frequentar a Biblioteca Móvel do Sesc. Outros 7 usuários indicaram que passaram a observar situações políticas, econômicas e sociais, que antes não eram percebidas, em que passaram a compreender e se posicionar melhor diante dos problemas sociais. Assim, esse resultado não apenas comprova que o BiblioSESC tem atingido seu objetivo de ser um ambiente mediador, como também de contribuir para ampliação da leitura do mundo por parte desses usuários, como afirmou Freire (2011), que reflete sobre a ideia da leitura do mundo anteceder a leitura da palavra, pois os indivíduos já não realizam a leitura apenas para si, mas compartilham os conteúdos dos materiais, leem para outros sujeitos que estiverem ao seu redor com uma capacidade de interpretar e representar o que está escrito.

Por outro lado, 4 usuários afirmaram que o BiblioSESC não contribuiu com seu desenvolvimento. Apesar de ser um número baixo em relação ao total de 
respondentes, deve ser revisto e apurado pela Biblioteca, na acepção de identificar a necessidade desses usuários.

A pesquisa investigou, como um de seus objetivos, as contribuições desta Biblioteca Móvel para a formação do leitor. 0 Gráfico 3 apresenta as respostas dos usuários sobre essa questão, sendo que um usuário poderia indicar mais de uma alternativa.

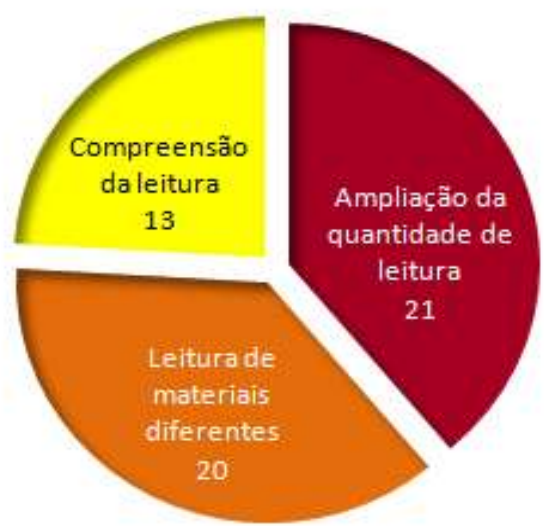

Gráfico 3: Contribuições do BiblioSESC para a leitura.

Fonte: Dados da pesquisa.

Entende-se que a compreensão da leitura é bem mais do que codificar signos, trata-se de desenvolver a perspicácia de relacionar o que se decodifica com informações e conhecimentos anteriores, associar e apreender essa nova informação com a realidade. Nesse sentido, 13 usuários informam que, por intermédio do BiblioSESC, passaram compreender melhor a informação, por meio da leitura. Outros 20 usuários informam que o BiblioSESC contribui com a prática da leitura através do acervo variado que disponibilizam.

Quanto às possíveis contribuições do BiblioSESC no aspecto social, conforme apresentado no Gráfico 4, dos 40 participantes da pesquisa, 22 indicaram uma melhor relação com as pessoas, 15 apontaram para um melhor desempenho na escola e 7 sobre a contribuição no trabalho.

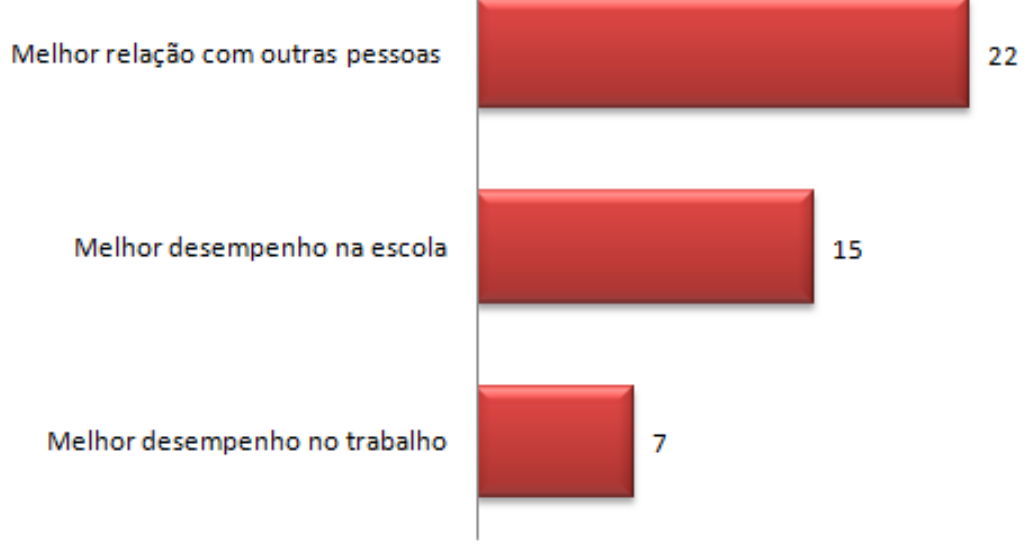

Gráfico 4: Contribuição do BiblioSESC no aspecto social.

Fontes: Dados da pesquisa. 
Os resultados apresentados no Gráfico 4 evidenciam que a Biblioteca Móvel favorece o desenvolvimento dos sujeitos residentes dos Bairros de Salvador. Dessa maneira, a Leitora D, no Bairro de Paripe, relata que, por causa de problemas pessoais, parou de estudar, ainda na adolescência. Voltou à escola, posteriormente, $\mathrm{e}$ enfrentou muitas dificuldades, entre elas, a de tornar a leitura um hábito e de realizar as pesquisas solicitadas pelos professores, até que conheceu a Biblioteca Móvel do SESC, indicada por sua mãe que passava pelo local e viu o caminhão. Daí em diante, toda a família se tornou frequentadora assídua.

O BiblioSESC foi uma nova oportunidade que tive em me aproximar da leitura novamente, aqui eu, minha mãe, minha filha e minha cunhada encontramos nos livros e nos materiais ofertados instrumentos que vêm nos ajudar com a nossa necessidade. (Leitora D)

A partir do relato da Leitora $\mathrm{D}$, pode-se afirmar que a Biblioteca não cumpre apenas seu papel de ambiente mediador, por seu acervo diversificado, ou pelo acesso às informações, mas também por auxiliar o usuário em sua formação e crescimento social, cognitivo e profissional. Cabe à Biblioteca identificar as várias necessidades informacionais dos usuários, entendê-los como um sujeito singular que precisa de auxílio no coletivo, mas também individual. Assim, realizando e ressignificando suas atividades e ações; disponibilizando materiais informacionais pertinentes, um espaço confortável e agradável para o desenvolvimento das atividades; e realizando uma comunicação direta e amigável, auxiliam os usuários e levam a biblioteca a atingir o lugar de ambiente de mediação da informação.

\section{CONSIDERAÇÕES FINAIS}

A análise dos resultados desta pesquisa sinaliza que ocorre o incentivo ao hábito da leitura por meio das atividades realizadas pela BiblioSESC nos Bairros de Salvador, pois, cumpre o objetivo estabelecido pelo projeto, que é encurtar o caminho do leitor ao livro, ao promover a leitura, ampliando as condições de acesso à informação. Com a pesquisa, também foi possível verificar o perfil social e cultural dos usuários, em que a maior parte destes que participaram da pesquisa estão no nível médio. Destaca-se que tais sujeitos estão em formação intelectual, com diferentes anseios e perspectivas de ascensão social, uma vez que residem em bairros menos favorecidos economicamente na cidade de Salvador, contudo, esses usuários buscam, por meio do BiblioSESC, o acesso aos livros e materiais informacionais, que lhes podem proporcionar um crescimento cultural, cognitivo e social.

Os resultados obtidos apontam indícios sobre a formação do sujeito leitor, posto que, a Biblioteca Móvel vem promovendo a melhoria da interação entre os sujeitos e o despertar do potencial crítico e da ampliação do gosto pela leitura, pois, com a aplicação do questionário junto aos usuários, foi identificado que os frequentadores passaram a se interessar mais pela leitura.

Durante a pesquisa, foi possível identificar como o ambiente proporciona a comunicação entre funcionários e usuários, pois compartilham vivências e experiências, entre outras ações, possibilitando a leitura da palavra e de mundo contribuindo para o desenvolvimento do hábito de leitura. Também pode-se afirmar que a Biblioteca tem favorecido que os usuários não apenas sejam leitores, mas mediadores da leitura e protagonistas sociais, pois, além de lerem, também têm influenciado outros a visitarem a Biblioteca e realizarem a leitura dos materiais disponíveis nesse ambiente.

Conclui-se ainda que, em relação as necessidades e motivações para a realização da leitura dos usuários do BiblioSESC, parte significativa destes leem por 
prazer, sem nenhuma demanda justificada, outra parcela de leitores, informaram que leem para obter conhecimento geral, e assim reafirma a importância do BiblioSESC, de manter o hábito da leitura, com o acervo variado e qualificado, favorecendo a uma prática cada vez mais prazerosa.

Na perspectiva da satisfação dos usuários, quanto às atividades e materiais disponíveis pela Biblioteca, os resultados obtidos nesta pesquisa apontam que o BiblioSESC tem cumprido um dos seus principais objetivos, que é a satisfação dos usuários. Ao atuar dessa maneira, o BiblioSESC cumpre o papel de ambiente mediador da informação, apresentando-se como um espaço acolhedor, que atrai os sujeitos, favorecendo o acesso e uso da informação.

Quanto às contribuições do BiblioSESC, no aspecto social, os respondestes indicaram uma melhor relação com as pessoas, além de um melhor desempenho na escola e no ambiente de trabalho. Através da trajetória investigativa, também tornou-se perceptível que os sujeitos compreendem a importância da leitura no cotidiano e percebem que não tiveram a oportunidade de ampliar a prática da leitura, pela existência de alguns fatores intervenientes. A partir desse sentimento demonstrado pelos usuários, cabe à Biblioteca auxiliá-los na ampliação do gosto e condições para realização da leitura. É necessário ampliar a possibilidade de uso dos materiais informacionais disponíveis pela Biblioteca, como também desenvolver ações que motivem a prática da leitura, como, por exemplo, a colaboração e interação entre os sujeitos.

\section{REFERÊNCIAS}

BORTOLIN, Sueli. 0 mediador da leitura. InfoHorme, 2007. Disponível em:

<http://www.ofaj.com.br/colunas_conteudo.php?cod=302 >. Acesso em: 20 set. 2016.

BORTOLIN, Sueli. Mediação oral da literatura: a voz dos bibliotecários lendo ou narrando. 2010. 234 f. Tese (Doutorado em Ciência da Informação) - Faculdade de Filosofia e Ciências, Universidade Estadual Paulista, Marília, 2010.

ALMEIDA JÚNIOR, Oswaldo Francisco; BORTOLIN, Sueli. Mediação da Informação e da Leitura. In: SEMINÁRIO EM CIÊNCIA DA INFORMAÇÃO, 2., 2007, Londrina. Anais eletrônicos...Londrina: UEL, 2007. Disponível em: < http://eprints.rclis.org/13269/> Acesso em: 22 set. 2016.

FREIRE, Paulo. A importância do ato de ler: em três artigos que se completam. 51 ed. São Paulo: Cortez, 2011.

GOMES, Henriette Ferreira. A dimensão dialógica, estética, formativa e ética da mediação da informação. Informação e Informação, Londrina, v. 19, n. 2, p. 46-59, maio./ago. 2014. Disponível em:

<http://www.uel.br/revistas/uel/index.php/informacao/article/view/19994/19090>.

Acesso em: 10 ago. 2010.

MARTINS, Maria Helena. o que é leitura. São Paulo: Editora Brasiliense, 1986.

RANGANATHAN, Shiyali Ramamrita. As cinco leis da Biblioteconomia. Brasília: Briquet de Lemos, 2009.

SANTOS, Raquel do Rosário. Espaço virtual e a comunicação com os usuários paramediação da informação: utilização pelas bibliotecas das universidades federais e estaduais brasileiras. 2012. 248 f. Dissertação (Mestrado em Ciência da Informação) Instituto de Ciências da Informação, Universidade Federal da Bahia, Salvador, 2012. Disponível em: <https://repositorio.ufba.br/ri/handle/ri/7833>. Acesso em: 10 ago. 2016. 
SILVA, Rovilson José da; BORTOLIN, Sueli. Das prateleiras às mãos dos autores. In: BARROS, Maria Helena TC; BORTOLIN, Sueli; SILVA, Rovilson José da. Leitura: mediação e mediador. São Paulo: FA, 2006. p. 17-22.

VILLARDI, Raquel. Ensinando a gostar de ler: e formando leitores para a vida inteira.Rio de Janeiro: Qualitymark-Dunya, 1999. 